\title{
Comparing the Extend of the Spread Effects: Rural-Urban Commuting in Finnish Working Regions
}

\author{
Olli Lehtonen, Olli Wuori, Toivo Muilu \\ Rural Policy and Research, Natural Resources Institute Finland, Helsinki, Finland \\ Email: olli.lehtonen@luke.fi
}

Received 6 January 2015; accepted 29 January 2015; published 2 February 2015

Copyright (C) 2015 by authors and Scientific Research Publishing Inc.

This work is licensed under the Creative Commons Attribution International License (CC BY). http://creativecommons.org/licenses/by/4.0/

(c) (i) Open Access

\begin{abstract}
It has long been posited that rural areas can benefit from nearby urban agglomerations through commuting, and that their development could be a side product of urban growth, but the results from the sparsely populated regions have not been promising. In this study, we investigate the possibilities of rural-urban commuting to support rural development, and explore the spatial ex-tent of the working regions if jobs are concentrated in the regional centre as indicated by recent trends. Spread effects are simply operated by an economic possibility to rural-urban commuting determined by a sum of housing and commuting costs from disposable income. The results show that the population growth in city regions does not extend to distant rural areas. It, instead, leads to population losses in remote areas due to backwash effects as the low disposable incomes encourage especially low-income households to migrate from remote locations closer to the centre. The spread effects seem to work only in the limited rural areas located next to the urban core which encourages the support of remote rural areas through place-based policy.
\end{abstract}

\section{Keywords}

Urban-Rural Commuting, Potential Spread Effect, Housing and Commuting Costs, Finland

\section{Introduction}

It has long been posited that one rural development strategy may be urban development as rural areas can benefit from nearby urban agglomerations through commuting [1]-[5]. However, results from the sparsely populated regions suggest that the extent of this strategy might be limited in sparsely-populated regions [6]. The extent (including geographic) to which rural communities can rely on nearby urban centres for employment and growth

How to cite this paper: Lehtonen, O., Wuori, O. and Muilu, T. (2015) Comparing the Extend of the Spread Effects: RuralUrban Commuting in Finnish Working Regions. Journal of Geographic Information System, 7, $29-42$.

http://dx.doi.org/10.4236/igis.2015.71003 
varies greatly depending on the urban centre's size, transportation network, topography, climate and distances from the set of competing urban centres [7]. However, previous studies have focused on commuters' characteristics, commuting distances and related factors [2] [7]-[9], but empirical studies focusing on the extent of urban spread effects on rural areas are lacking.

In theory, the expansion of the urban structure hinges on the tradeoff between land rent and commuting costs. Increasing commuting opportunities require lower housing costs at the urban fringe to offset the higher commuting cost to the urban core. Compensation of the increasing commuting costs is important because the household selections between commuting and migration from rural view have very different impacts on population and different implications for regional policy and planning. For example, a significant decrease in local labour demand may induce mobility to other regions. The impacts of this mobility on the municipality's tax base and housing market depend on the individual's possibilities and choice between migration and commuting. The literature has revealed that the likelihood of commuting increases significantly with the interregional accessibility to job opportunities, and is also more likely for people living in metropolitan areas than migration [8]. Also, lower rural or exurban housing prices have attracted new residents from the urban centre, who retain their urban jobs and commute to work in the centre [10] [11].

The contribution of this paper is the use of an urban hierarchy context to disentangle the local job growth versus population growth effects on rural out-commuting in Finland and to consider based on our findings rural development policy implications. We investigate the possibilities of rural-urban commuting to support rural development based on housing and commuting costs, and explore the spatial extent of the working regions if jobs are concentrated in the regional centre as in recent trends. In our definition, the spatial extent of the working region defines the region where potential spread effects or positive spillovers from urban growth can be directed to rural areas. Potential spread effects are simply operationalized by an economic possibility to rural-urban commuting determined by a sum of housing and commuting costs from disposable income. The spatially uneven employment growth in Finland, as in the shift to knowledge-based economy in the 1990s, is likely to promote strong migratory and commuting responses, as relatively advantaged workers seek out employment opportunities. It also underlines the importance of commuting opportunities for rural areas. Based on the observed development trends it has long been posited that one rural development strategy may be urban development as rural areas can benefit from nearby urban agglomerations through commuting [1]-[5].

In the following chapters, we present the theoretical background of the study. Next we present a description of study regions and urban-rural classification. Then we present the results of the analysis. In the ending section, we discuss the results of the study and point at their theoretical and practical implications.

\section{Theoretical Backgrounds}

At present, most local labour markets in Finland are experiencing a downturn in the supply of competent labour as well as a rising unemployment level [12]. During the past years, only knowledge-based economy centres have had competitive advantages in terms of the availability of labour, economies of scale and industrial structure, and, therefore, most new jobs are located in these centres [13]. As employment opportunities in rural areas are declining, increased inter-regional commuting could be vital to improving the job-matching process and helping to create more competitive and larger regions. For instance, in disadvantaged areas of Northern Ireland, researchers found significant participation by rural dwellers in the nearby urban labour market, and concluded that facilitating access to town should be a clear policy priority for rural development [1]. Without access to sufficient quality roads, governments and residents of rural areas will either need to develop their local economies, or to look towards larger urban centres in order to survive. Clearly, many remote rural areas have insufficient critical mass to sustain themselves, indicating that access to commuting may be the only viable outcome for a sustainable livelihood [2]. Another important issue is that possibilities to commute long distances from sparsely populated areas are more limited for reasons of distance and access to public transportation compared with metropolitan and other more densely populated areas [14].

A common explanation for recent urban-rural population development and location for new industries is based on agglomeration economies and knowledge spillovers in urban centres [15]. The agglomeration economies, urban amenities and economic structure that are found in large cities promote local economic success. Economies of scale and scope in economic activity and in the provision of amenities generate urban advantages that perpetuate the concentration of economic activity and population in, and in closer proximity to, them [4]. The growth of the city will benefit broader regions with access to these advantages. Thus, the "engine of growth" 
statement is linked to the changing role and cost of distance in the information economy, and related issues such as customer accessibility and access to higher-order producer services [4] [16] [17]. The cumulative concentration of jobs has increased the hopes for rural areas to benefit from the urban agglomerations. However, in distant rural areas the focus is on agglomeration economics independent economic activities or alternatively on declining the friction of distance. In Finland, only the natural resource-based growth and tourism have had similar probabilities for the increase of jobs in the centre and rural areas, but these new jobs have not been able to cover the job losses in agriculture, forestry and industry [13].

From a rural development perspective, the interest in commuting is typically related to the extent to which rural households can benefit from urban agglomeration economies through access to employment opportunities, while maintaining a rural residence [7]. This topic is discussed in neo-classical spatial-economic urban models, where the situation of households' residential location is a result of the trade-off between commuting costs and preferred housing costs [18]-[20]. A central assumption of these traditional models is that wages, housing prices and population densities fall outside a central business district. Accordingly, commuting is determined by the equilibrium state between housing and labour market, where the monetary and mental costs of commuting are compensated through the housing market. Households may, therefore, choose to locate further from work and have greater commuting costs in exchange for lower housing costs. Several studies that have focused on the relationship between commuting and residential location show that longer commutes are also chosen as part of housing preferences. For example, a study on commuting decisions about the dual-earner households shows that spouses jointly chose longer commuting distances as part of preferred housing and neighbourhood characteristics [21]. In Finland, similar findings have also been observed [22]. Furthermore, lower rural or exurban housing prices attract new residents from the urban centre, who retain their urban jobs and commute [10] [11].

Extended, or rural-to-urban, commuting is often cited as an example of the spillovers of urban growth [7]. Spread and backwash have been used respectively to describe the positive and negative effects of urban growth on the rural areas [23]-[25]. In this view, rural-to-urban commuting decisions are closely related to local employment prospects, access to urban employment and the other location attributes of both rural and accessible urban areas. Of course, the residential location decision is also closely tied to the commuting-to-work possibilities [8]. Positive spillovers (spread) occur when rural population and employment increase as a result of commuting, population migration and firms and households fleeing urban congestion and high costs. Reference [26] found that in the U.S. state of North Carolina, the movement of urban population to rural areas (deconcentration) increased the geographic extent of urban commuting sheds. Evidence from Canada suggests that a large share of rural areas that experience job and population growth are near urban centres (say within $120 \mathrm{kms}$ ), especially large centres, and that commuting from rural places-of-residence to urban places-of-work can "decouple" local job and population growth [27]. Thus, local population growth may no longer be so dependent on local job growth, but instead on job growth in urban places within commuting distance, leading to geographically large regional labour markets [5] [11] [28]. For rural areas near urban centres, the means of population growth may be their best rural development strategy.

\section{Working Regions and Definition for Rural Areas in Finland}

Finland is an interesting case for the study at hand. It is a classic example of a western country which has strong presumptions of the spread effects created by regional centres supported by regional policy. The National Innovation System was based on establishing the Centres of Excellence in a few, large urban areas and favouring experimental research and development in companies. The regional policy paradigm supposes that various regional centres spread success in their surrounding areas. This should take place directly or via knowledge spillovers to companies, thus finally improving household incomes and at the end quality of life. Since 1994, eight urban-based centres of expertise have been created in Finland for the incubators of regional development, but the majority of funding was allocated to the largest urbanised nodal areas of Helsinki, Turku, Tampere and Oulu. The policy of the centres of expertise expanded to 14 centres in 1998 and to 22 in 2003 as the aim of the policy was to cover geographically almost the entire country aiming at avoiding the formation of idle human resources. However, the analysis of the policy has shown that in recent years emphasis has been instead of territorial cohesion in the competitiveness of regional centres and innovation policy [29].

The areal unit of our analysis is postcode area, which constitutes the smallest regional statistical entity based on functionality in the distribution of a service, here the postal service of Finland. The most commonly used geographical unit in Finnish regional analyses is the municipality, but because each municipality is rather hete- 
rogeneous in terms of housing costs, it is justified to use smaller and more homogeneous areal units in order to observe the spatial patterns of living cost. The data on the averages of household disposable incomes, commuting distances and housing sizes were derived from the SuomiCD database consisting of 2669 postcode areas. The postcode area was the smallest spatial unit which contained information about housing prices and had enough large housing markets, and so also included rural areas. The greater problem with smaller spatial units than postcode areas, like statistical grid cells, is that due to small housing markets, the coverage of the data would be sparse and probably highly random in rural areas. Housing prices in 2010 and 2011, which are used in the calculation of housing cost, were based on the market prices from the housing markets.

\subsection{Working Regions}

In this paper, we will focus on three working regions—Helsinki, Turku and Joensuu—which all represent the different centres of expertise and city sizes (Figure 1). Working regions are based on the definition of Statistics Finland for the year 2013 and they are modelled separately because in terms of housing costs, there has been
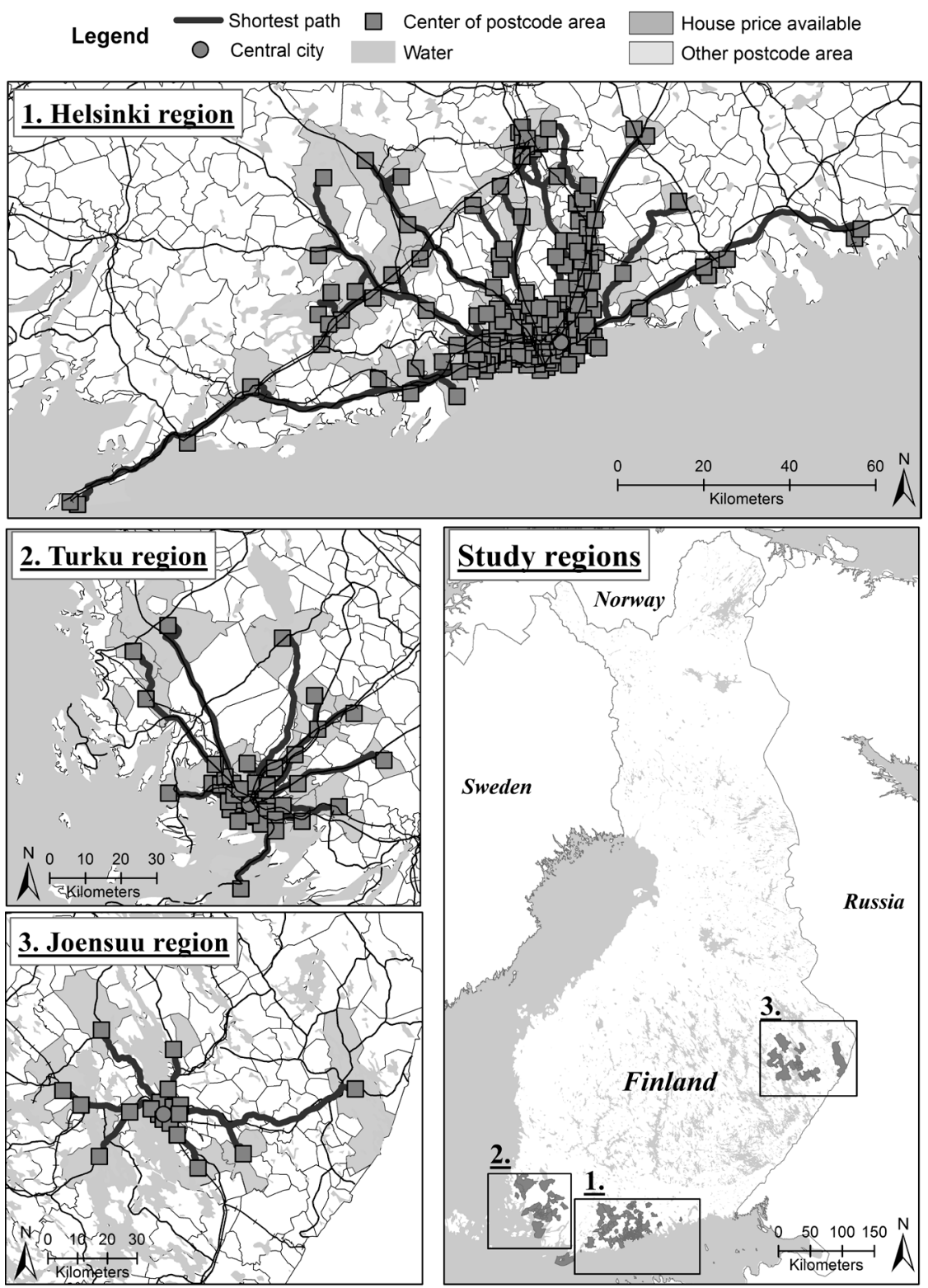

Figure 1. Working regions and their location in Finland. 
found great variation within working regions in Finland [30]. The analysis focus on working regions as it allows deeper understanding about the potential spread effects in micro-scale. The selection criterion of regions was related to the assumption that the size of the centre will have an impact on the extent of spread effects. Previously, reference [7] found that the larger urban centres have larger 'footprints' in rural space and that all urban places see their attraction as commuting destinations dissipate with distance. Statistics about the used working regions are collected in Table 1. Also the difficulties acquiring a decent database for analysis forced us to concentrate on these selected working regions.

\subsection{Definition for Rural Areas in Working Regions}

Defining rural areas has for a long time been a subject of study and no common definition suitable for all countries and different territorial contexts exist [31]. In this paper, we define rural areas as being outside of urban areas which include the central urban core, suburbs and exurban fringe. This means that rural areas are defined as being outside of the area that most likely benefit from urban sprawl, or, in other words, from where people currently commute to urban areas. Postcode area typology is done with cluster analysis being commonly employed in geography to reduce a large number of areas to clusters that are internally as homogeneous as possible [32]. In our case, the cluster analysis was based on two variables: distance to the regional centre and average distance to jobs (Table 2). These variables were used as they fit the above classification of postcode areas. In theory, the centre and suburbs should be areas whose distance to the centre and workplace is relatively small. The exurban fringe should consist of areas that locate further away from suburbs and whose trips to work are rather long due to greater commuting distance from the centre. The rural areas are described as being located far from the centre and having low commuting distance to the centre because of the declining frequency of rural-urban commuting.

For the purpose of cluster analysis, all the values of the variables that are included have to be standardized to $\mathrm{z}$-scores with a mean of 0 and a standard deviation of 1 . Otherwise, the distance to the regional centre with the largest values would dominate the clustering solution. Since the method employed here does not make any distributional modifications, no other transformations of the data were performed. To order the postcode areas into the above classification, a K-means cluster analysis was performed. K-means clustering aims to partition the

Table 1. Statistics about the working regions.

\begin{tabular}{cccccc}
\hline Region & $\begin{array}{c}\text { Population } \\
2011\end{array}$ & $\begin{array}{c}\text { Population change } \\
2000-2011(\%)\end{array}$ & $\begin{array}{c}\text { Average square } \\
\text { price 2010 }(€)\end{array}$ & $\begin{array}{c}\text { Average income of } \\
\text { household 2011 }(€)\end{array}$ & $\begin{array}{c}\text { Lower quartile of } \\
\text { average incomes 2011 }(€)\end{array}$ \\
$\begin{array}{c}\text { Longest distance } \\
\text { from centre }\end{array}$ \\
Helsinki $(n=201)$ & $1,290,970$ & 11.7 & 2801 & 43,098 & 32,869 \\
Turku $(n=46)$ & 288,157 & 7.1 & 1645 & 34,891 & 26,720 \\
Joensuu $(n=21)$ & 90,213 & 1.8 & 1428 & 28,977 & 24,597 \\
\hline
\end{tabular}

Table 2. Descriptive statistics of original variables by clusters.

\begin{tabular}{|c|c|c|c|c|c|}
\hline Region & Variable & Centre & Suburbs & Exurban fringe & Rural \\
\hline \multirow{3}{*}{ Helsinki } & Average distance to regional centre & 8.87 & 8.95 & 34.52 & 66.76 \\
\hline & Average distance to work & 6.91 & 5.19 & 10.17 & 7.69 \\
\hline & $n$ & 77 & 60 & 45 & 19 \\
\hline \multirow{3}{*}{ Turku } & Average distance to regional centre & 7.88 & 8.45 & 32.05 & 53.36 \\
\hline & Average distance to work & 6.20 & 8.37 & 8.96 & 7.26 \\
\hline & $n$ & 19 & 14 & 8 & 5 \\
\hline \multirow{3}{*}{ Joensuu } & Average distance to regional centre & 4.66 & 6.55 & 28.55 & 47.12 \\
\hline & Average distance to work & 7.20 & 6.37 & 8.85 & 8.92 \\
\hline & $n$ & 6 & 7 & 4 & 4 \\
\hline
\end{tabular}


points into $k$ groups such that the sum of squares from points to the assigned cluster centres is minimized. Here, the $k$ was set to 4 based on typology discussed above. Clustering was based on Hartigan-Wong algorithm with 20 random starts and 50 iterations to find the best start for clustering [33], and stability for clustering. The empirically grounded four-cluster solution consists of clusters named centre, suburbs, exurban fringe and rural areas (Table 2).

The areal classification gives a more structural view of the current regional differentiation than single statistics from the postcode areas. The centre areas are the most populous cluster where the housing prices are also high (Table 3). At least partly due to congestion, the population growth has been lower compared with suburbs or exurban fringe (Table 2). However, the population has still grown in Helsinki and Turku regions (Table 3). Compared with the suburbs and fringe areas the population in the centre is also older and the average size of the households is smaller. Due to age structure, the disposable incomes are also lower than in suburbs and fringe areas. The cluster of suburbs is the only one where the total population and number of jobs have increased in every working region (Table 3). Young people with families have moved to the suburbs, as the low average age indicates. These areas are located in the travel-to-work area of centres, but outside the core of the city itself as average distances to work and the regional centre are demonstrating (Table 2).

Postcode areas in exurban fringe areas are located in the fringe of the travel-to-work areas. These postcode areas are in Helsinki and Turku regions characterised by the highest disposable income of households, largest family and house sizes (Table 3). The high income level indicates better economic resources to cope with commuting costs. The size of the centre municipality seems to have an effect on population growth as in Helsinki and Turku the growth has been the highest in exurban fringe, while in Joensuu the population growth has

Table 3. Descriptive background of the clusters.

\begin{tabular}{|c|c|c|c|c|c|}
\hline Region & Variable & Centre & Suburbs & Exurban fringe & Rural \\
\hline & Average population of postcode areas & 7213.89 & 6933.98 & 5675.26 & 4434.89 \\
\hline \multirow[t]{9}{*}{ Helsinki } & Population change (2008-2010) & 0.52 & 1.74 & 1.35 & 0.21 \\
\hline & Average age & 39.71 & 36.56 & 36.48 & 42.05 \\
\hline & Family size & 2.09 & 2.17 & 2.44 & 2.05 \\
\hline & Mean disposable income of households ( $€$ ) & 41523.92 & 44790.90 & 47490.84 & 33725.11 \\
\hline & House price $\left(€ / \mathrm{m}^{2}\right)$ & 3214.24 & 3374.26 & 2214.57 & 1690.78 \\
\hline & Average house size $\left(\mathrm{m}^{2}\right)$ & 73.89 & 76.45 & 92.4 & 80.00 \\
\hline & Average population of postcode areas & 6609.89 & 8511.85 & 3840.00 & 3130.20 \\
\hline & Population change (2008-2010) & 0.25 & 1.26 & 1.32 & -2.79 \\
\hline & Average age & 41.63 & 38.64 & 40.00 & 42.80 \\
\hline \multirow[t]{7}{*}{ Turku } & Family size & 2.03 & 2.07 & 2.32 & 2.16 \\
\hline & Mean disposable income of households $(€)$ & 33132.95 & 35444.86 & 40669.50 & 30779.20 \\
\hline & House price $\left(€ / \mathrm{m}^{2}\right)$ & 1655.36 & 2066.43 & 1454.00 & 997.20 \\
\hline & Average house size $\left(\mathrm{m}^{2}\right)$ & 78.63 & 79.64 & 97.75 & 92.20 \\
\hline & Average population of postcode areas & 4966.33 & 5191.14 & 2191.75 & 3999.50 \\
\hline & Population change (2008-2010) & -2.05 & 2.51 & -2.22 & -2.83 \\
\hline & Average age & 33.33 & 37.42 & 43.00 & 46.75 \\
\hline \multirow[t]{4}{*}{ Joensuu } & Family size & 2.10 & 2.10 & 2.17 & 1.97 \\
\hline & Mean disposable income of households (€) & 30881.17 & 30941.71 & 27625.25 & 24036.50 \\
\hline & House price $\left(€ / \mathrm{m}^{2}\right)$ & 1739.16 & 1981.14 & 991.75 & 926.50 \\
\hline & Average house size $\left(\mathrm{m}^{2}\right)$ & 78.50 & 78.85 & 82.00 & 77.50 \\
\hline
\end{tabular}


been negative in this cluster. This seems to indicate that the spread has not extended to the exurban fringe in Joensuu working region. In Helsinki and Turku regions the exurban fringe seems to be growing and clearly benefiting from the spread effects generated by centres.

In terms of typology, the rural areas are located a long distance from the centre of the working region, and have been severely restructured by the out-migration and ageing of the population (Table 3). The population change has been most negative or smallest (Helsinki region), and on average the population is oldest compared to other clusters. The economic and societal structures are deteriorating, and they have also faced substantial restructuring, which will probably lead to decline in the future. Postcode areas belonging to this cluster seem to be marginal areas from the view point of commuting to the centre, and the friction of distance seems to have the highest impact on development.

\section{Empirical Implementation}

\subsection{Calculation of the Housing and Commuting Costs}

In earlier studies, the potential spread effects are mostly operationalized by the growth of population or jobs [7] [23]-[26]. In this paper, we created a new practical way of operationalization the potential spread effects based on the sum of housing and commuting cost, which cannot be more than 80 per cent of the household incomes as households are spending 20 per cent of the incomes for basic living including food, health and communication [34]. However, most probably potential spread effects weaken earlier as the household cannot long term use 80 per cent from its incomes for housing and commuting because otherwise it has not left enough resources for basic living. Therefore, the potential spread effects weaken, for instance, if the housing and commuting proportion is over 60 per cent. According to statistics, about 43 per cent from incomes are spent on housing and commuting [34]. The proportion of housing and commuting costs from household income $\left(D_{i}\right)$ is calculated by subtracting state taxable incomes $\left(I_{i}\right)$, housing costs $\left(L_{i}\right)$, commuting costs $\left(C_{i}\right)$ and municipality taxes $\left(T_{i}\right)$, and dividing this by incomes multiplied by 100 . By equation, this can be written as

$$
D_{i}^{n}=\frac{I_{i}-L_{i}-C_{i}^{n}-T_{i}}{I_{i}} \times 100
$$

where $C_{i}^{n}$ denotes average commuting cost calculated based on average commuting length of postcode area. Respectively, the disposable income of average household in postcode area in situation when location of jobs is changed to highest job concentration postcode area is calculated by substituting $C_{i}^{n}$ with $C_{i}^{k}$. By comparing these alternative commuting costs, we can estimate the potential spread effects with rural-urban commuting opportunities. This estimate will also indirectly describe the impact that concentration of jobs might have on household's disposable income.

Housing costs $\left(L_{i}\right)$ are calculated as the sum of capital expenditure $\left(P_{i}\right)$ and treatment costs $\left(K_{i}\right)$ [35]

$$
L_{i}=P_{i}+K_{i}
$$

Capital expenditure consists of mortgage repayments as well as mortgage interest rates. Care expenses are included in the calculation of energy and other energy costs, property taxes and water and waste charges. The latter costs are difficult to estimate reliably by postal code or by municipality, so we use the general housing costs defined by Social Insurance Institution of Finland based on the calculation of the housing allowance [36]. The care expenses of the residence are calculated per $\mathrm{m}^{2}$, which means that differences in the average sizes of houses have impact on these expenses. The use of general costs is justified by the fact that their share of the total cost of housing is, in spite of municipality-specific variations, small. Real estate taxes are calculated by municipalities from valid taxes for 2011. Calculation uses the statistics of average building lots and site cost from the national land survey of Finland. Calculation of the housing cost is based on owner-occupied housing, which was, in the years 2010 and 2011, exceptionally cheap in Finland compared with rented housing [30].

According to the Equation (1), the living cost will also depend on the cost of commuting to work. These costs are calculated in two alternatives, one of which describes the current situation with average commuting distances and the second which describes the situation when the household's jobs are located in the postcode area with the highest job concentration in the working region. Thus, the calculation reminds a theoretical model of the central business district (CBD) where jobs tend to concentrate on certain areas. Commuting costs are calcu- 
lated as a product of current average distance to job $\left(d_{i}^{n}\right)$ and unit cost of distance $\left(c^{d}\right)$ subtracted by tax deduction from travelling expenses $\left(m_{i}\right)$

$$
C_{i}^{n}=d_{i}^{n} \times c^{d}-m_{i}
$$

The average commuting distance by postcode areas was gathered from the SuomiCD database. The unit cost of the distance was based on the estimate of the Automobile and Touring Club of Finland as regards the cost per kilometre, which in 2010 amounted to $0.42 € / \mathrm{km}$. Commuting costs are calculated by car because rural areas, in particular, often lack regular public transport, so the use of a car is the only option, and, therefore, private cars are the most commonly used for travelling. The private car is also the most common means of transportation in Finland, as the days of travel distance by car is 72 per cent [37]. This is also the reason why tax deduction is calculated based on the use of a private car for commuting. In 2010, compensation for the use of a car was 0.25 $€ / \mathrm{km}$. However, tax deduction based on the tax rate is limited so that compensation is paid when the travel expenses exceed the $600 € /$ year, and the upper limit for compensation is set at $7000 €$ year.

Similarly, the commuting cost to the centre was calculated by multiplying the distance between the postcode area and the centre $\left(d_{i}^{k}\right)$ and unit cost $\left(c^{d}\right)$, and then subtracting tax deduction from travelling expences $\left(m_{i}\right)$

$$
C_{i}^{k}=d_{i}^{k} \times c^{d}-m_{i}
$$

The distance to the centre was calculated along the road network based on the Digiroad database with ArcMap 10.1. The calculation of the model was created with statistical program $R$. The results of the calculations are approximate because due to data sources the analysis focuses on the average household's living parameters as regards the house size, house prices, household disposable incomes and commuting distances. However, the methodology still provides estimates for the inter-regional differences in housing and commuting costs, as well as their impact on the household's disposable income, and, ultimately, concretely information about the potential spread effects of the centre from the rural view.

\subsection{Estimation of the Housing and Commuting Costs with Non-Parametric Local Polynomial Regression Model}

The sum of the housing and commuting costs in working regions is analyzed using the local polynomial models. These models are used to estimate the curves that describe the dependence of housing and commuting costs respect to distance from the centre. By comparing the estimated curves of these models, we can test first and second hypotheses. The used method belongs to the family of nonparametric methods, whose objective is to relax assumptions on the form of a regression function and to allow data search for a suitable function that describes the data well. Reference [38] argued that this explanatory character is the best benefit of nonparametric modelling as it does not need any presumptions about the function, according to which the model is reconciled. Compared with linear or exponential regression methods, local polynomial models ignore the strict assumptions regarding to statistical independence of the errors, homoscedasticity and normality of the error distribution. Small data sets, as in this study (see Table 1), increase the likelihood of these assumptions to be violated and if these assumptions are violated, the regression results about the housing and commuting costs may be seriously biased or misleading.

In addition, the method's flexibility makes it ideal for the modelling of complex phenomena, especially in cases where the theoretical model or distribution does not exist like in our case (ibid.). The aim of the local polynomial models is to approximate locally the dependent variable $(f(D))$ (housing and commuting cost) with different polynomials by independent variable $x_{0}$ (distance to the centre). The results are presented visually because unlike parametric models the model does not estimate stationary regression coefficients. Thus, the method can sometimes be described as "non-stationary" as the estimated curve can reveal locally changing associations. The method is also suitable for small data sets [38].

More precisely, the used local polynomial regression of $y$ (housing and commuting costs) on $x$ (distance from centre) can be written as

$$
f(D) \approx \beta_{0}(x)+\beta_{1}(x)(D-x)+\beta_{2}(x)(D-x)^{2}+\cdots+\beta_{p}(x)(D-x)^{p}
$$


weighting the observations in relation to their proximity to the focal value $x_{0}$. Here, we use a common weight function named tricube function:

$$
w(t)= \begin{cases}\left(1-\left|t^{3}\right|\right)^{3}, & \text { for }|t|<1 \\ 0, & \text { for }|t|>1 .\end{cases}
$$

where $t_{i}=\left(x_{i}-x_{0}\right) / h$. The $h$ is the half-width of a window enclosing the observations in the local regression. Typically, the $h$ is adjusted so that each local regression includes a fixed proportion $\mathrm{s}$ of the data. Therefore, $s$ is called the span of the local-regression smoother. The larger the span is, the smoother the result, and, conversely, the larger the order of the local regressions $p$ is, the more flexible the smooth. In this weighting function the observations which are further located than bandwidth $(h)$, get a weighting value 0 . This means that they do not have an impact on local estimation at point $x_{0}$. We used the closest neighborhood estimation for models because it was suitable for sparse data [39]. The model was estimated with $R$ and its base stats library.

\section{Results}

\subsection{Sum of Housing and Commuting Costs with Respect to Distance from Centre}

In the current situation, when the commuting to the centre is not dominating in the distant postcode areas, the differences between the households living in the centre and in the distant areas are relatively low as the estimated curve of the sum of housing and commuting costs with respect to distance from the centre is flat (Figure 2). Explanation for small differences is that the short average commuting distances in the distant (rural) postcode areas keep the commuting costs relatively low because the commuting is still concentrated in smaller local centres located less than 10 kilometres from their place of residence. Therefore, commuting costs take only a small proportion from costs and disposable income is mainly defined by housing costs. Thus, due to short commuting trips and lower housing costs compared with urban areas the disposable income in distant areas is either higher or at least the same level with the centres (Figure 2). At its lowest, housing and commuting costs account for 45 50 per cent of a household's incomes, which are close to what another Finnish study has observed in municipals [40].

The deeper evaluation of the estimated curves shows that working regions have some differences in the housing costs. For instance, in Helsinki region, the housing costs are the highest in the postcode areas located in the very centre and about 20 kilometres from the centre. The postcode areas located within these distances have disposable income ranging from 55 - 65 per cent of the total incomes (Figure 2). In Turku working region, the highest costs are located $15 \mathrm{~km}$ from the centre, and in Joensuu, about $10 \mathrm{~km}$ from the centre (Figure 2), with disposable income ranging from about 40 - 50 per cent of revenue between households. These differences are likely to indicate socio-economic differences between housing zones within the regions. In Helsinki region, the housing prices are considerably higher in the centre compared with other working regions, which is directly reflected in the household's disposable incomes (Figure 2). In other regions, the highest housing costs are located 10 - 15 kilometres from the city centres, where the residential buildings are mostly detached houses. Also, the income level of the households has direct impact on the disposable incomes (Figure 3). The disposable incomes of the households living in the upper limit of the lowest quartile are naturally considerably smaller than those of the average households. Declining disposable incomes is a product of the relative decline on incomes, where housing and commuting costs represent a relatively larger proportion of middle-income earners as housing cooperatives.

When the household's jobs are located in the centre like in CBD model, the disposable income is the highest in the postcode areas located in the centre or in the immediate neighborhood of it. Except for the Helsinki working region, the sum of the housing and commuting cost is the lowest in the centre. In Helsinki region, the lowest sum of housing and commuting costs can be achieved in postcode areas located about $10 \mathrm{~km}$ from the centre (Figure 2 and Figure 3). The differences inside the working regions are not such big in the housing costs that they would defeat the increasing costs of commuting. However, because of the deductible reimbursement of travel expenses the commuting costs increases sharply when the distance from the work area center exceeds 30 40 kilometers (Figure 2 and Figure 3). After this zone, the imaginary slopes of the locally estimated curves become larger which means that commuting costs have higher impact on disposable income and the impact of distance strengthens. The result shows that tax incentive is not planned to support wide spread effects. 

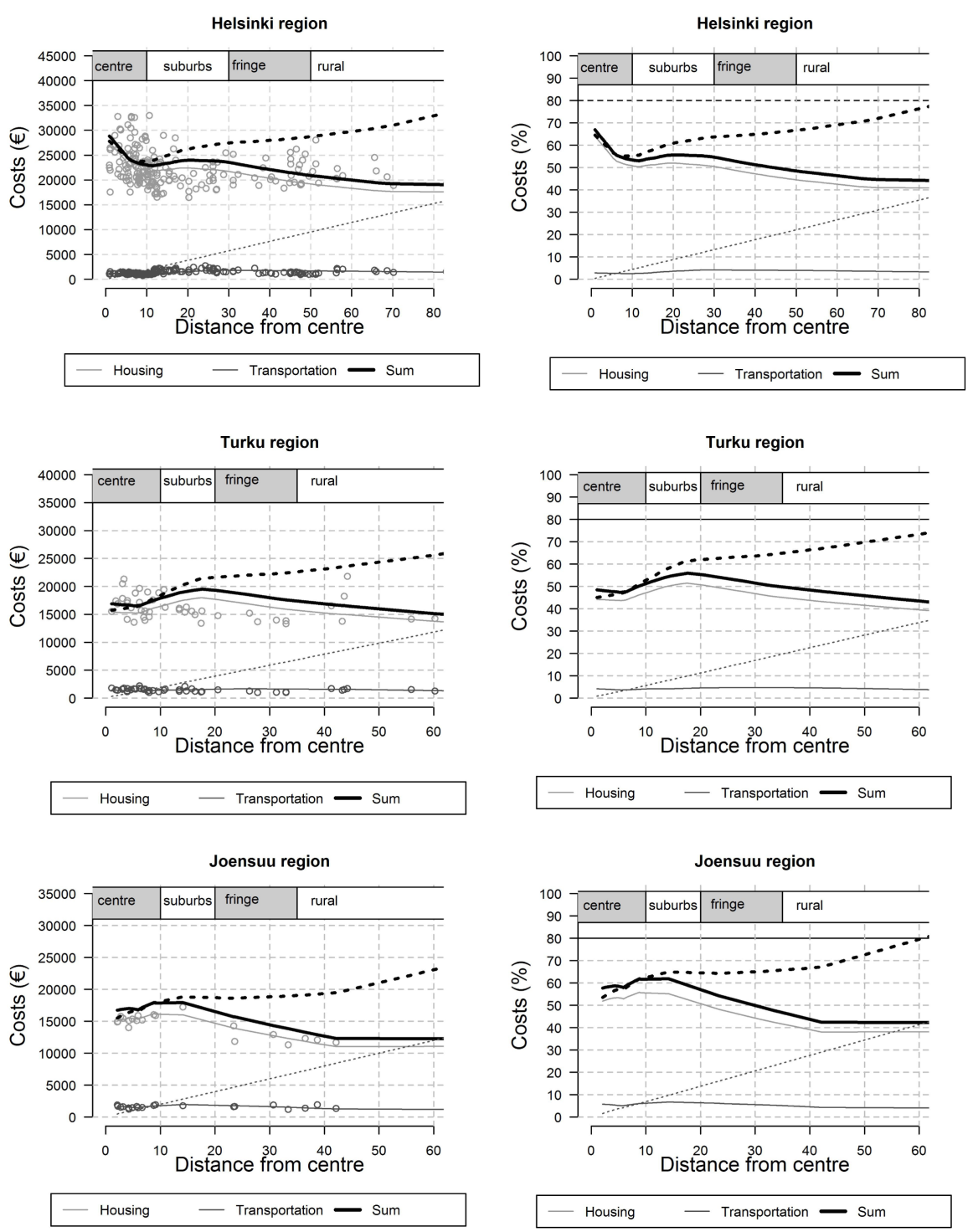

Figure 2. Housing and commuting costs with respect to the distance from centre of household with average incomes. Dotted line refers to situation when commuting is directed to centre.

Helsinki region

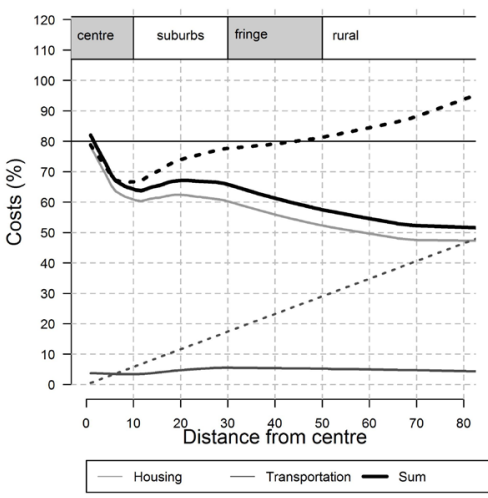

Turku region

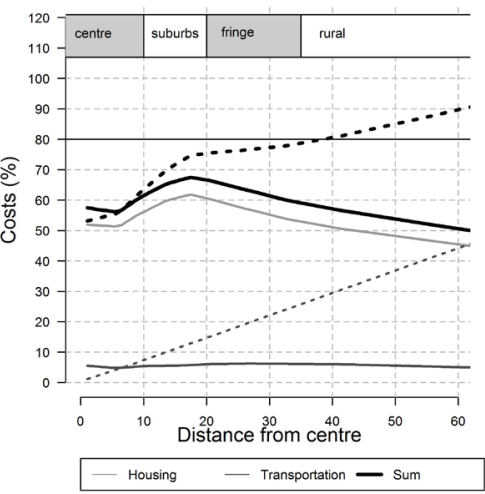

Joensuu region

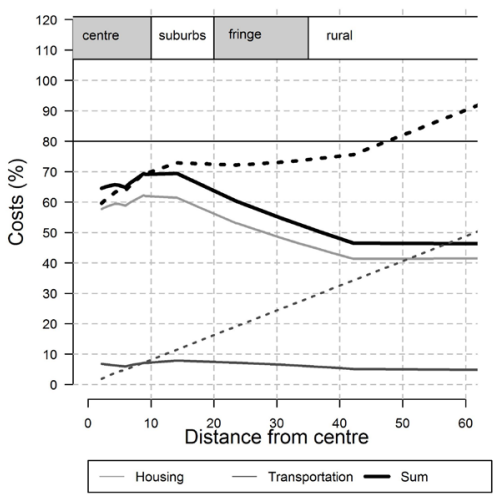

Figure 3. Housing and commuting costs with respect to the distance from centre of household with upper limit quartile incomes. Dotted line refers to situation when commuting is directed to centre. 
The disposable income is lowest in the remotest areas as the increasing commuting cost cannot be equalised by declining housing costs (Figure 2 and Figure 3). Because housing costs are not reduced in the same way as the commuting cost increases, the curves show that especially after 30 - 40 kilometres, the remote areas are unfavorable locations for housing if commuting is directed to highest job concentration postcode area in the working region. Therefore, the households living in the most distant areas would increasingly use most of their incomes on commuting costs and thus, they might find it more advantageous to move to the centre or its immediate surroundings to decline commuting costs. In fact, in some areas the commuting costs can become so high that the commuting is not economically possible as the housing and commuting costs took over 80 percent (Figure 2 and Figure 3), which mean that household has not left enough resources to spend on food, telecommunications and health (Statistics Finland, 2013). This indicates that for maintaining the job the household has no other option except migration closer to job concentration area to decline commuting costs. In particular, the problem relates to low-income unemployed households which have to use a relatively high proportion of their income for housing and commuting (Figure 2 and Figure 3).

The results are somewhat inconsistent with the new legislation as an unemployed person is obliged to accept a job within $80 \mathrm{~km}$ radius of their place of residence, while the results showed that for low-income households it may not be economically feasible to do such long commutes. As regards the middle-income household, the outer limit for commuting is, for example, in Joensuu working region, located about 60 kilometres from the centre. In particular, the problem concerns households with low income level because housing and commuting costs are relatively higher for these households. For the households living in the limit of lower quartile, the commuting is possible to more restricted area. and the limit is reached about 45 kilometres from the centre (Figure 3). Due to higher housing costs, in Helsinki and Turku working regions, the same limit for lower quartile is reached about $40 \mathrm{~km}$ from the centre at the same point where the impact of tax incentives seems to stop (Figure 3).

\subsection{Sum of Housing and Commuting Costs of the Households by Urban-Rural Clusters}

The results by classification correspond to previous view of limited spatial extend of potential spread effects and show that rural areas have only small opportunities to benefit from jobs in urban areas even when the rural areas are located inside the working regions (Table 4). Comparison shows that in every working region, the rural areas have the highest living cost when the household's jobs are located in the centre. Depending on the working region, these costs are 33 - 39 per cent higher than currently when the commuting is towards local centres (Table 4). Rise of the commuting costs would increase the losses of households living in rural areas. Most importantly, the absolute changes in the sum of housing and commuting costs would also be highest in rural areas, while they are lowest with current commuting cost. For instance, in Turku region difference between centre and rural areas would be about $7000 €$ (Table 4). Thus, results show that in a sparsely populated country like Finland, hopes about the access of rural areas to urban-based employment are improbable, which underlines the success of local labor markets and the importance of local practices in regional and rural policies supporting their development.

Table 4. Average housing and commuting costs by clusters and their percentage change compared with current costs.

\begin{tabular}{|c|c|c|c|c|c|c|}
\hline Region & Variable & & Centre & Suburbs & Exurban fringe & Rural \\
\hline \multirow{3}{*}{ Helsinki } & Cost with current commuting distance & $€$ & 23,687 & 24,365 & 22,662 & 19,914 \\
\hline & \multirow{2}{*}{ Cost with commuting to centre } & $€$ & 24,234 & 24,955 & 27,616 & 31,086 \\
\hline & & $\Delta \%$ current & 2.3 & 2.4 & 17.9 & 35.9 \\
\hline \multirow{3}{*}{ Turku } & Cost with current commuting distance & $€$ & 17,089 & 17,786 & 18,142 & 16,192 \\
\hline & \multirow{2}{*}{ Cost with commuting to centre } & $€$ & 17,131 & 18,170 & 20,932 & 24,136 \\
\hline & & $\Delta \%$ current & 0.2 & 2.1 & 13.3 & 32.9 \\
\hline \multirow{3}{*}{ Joensuu } & Cost with current commuting distance & $€$ & 16,952 & 17,293 & 14,750 & 12,812 \\
\hline & \multirow{2}{*}{ Cost with commuting to centre } & $€$ & 16,387 & 16,939 & 18,808 & 20,901 \\
\hline & & $\Delta \%$ current & -3.4 & -2.1 & 21.6 & 38.7 \\
\hline
\end{tabular}


Results in Table 4 confirm that the postcode areas located in the exurban fringe seem to be the remotest ones that could benefit from potential spread effect of the urban areas. In this cluster, the increase of housing and commuting costs are 13 - 22 per cent (Table 4). The increase is the highest in Joensuu, which is the smallest working region. The differences of exurban fringe compared with rural areas are the smallest in Joensu region where the difference is about $2000 €$ (Table 4). In other regions, the differences are at minimum over $3200 €$. In the clusters of the centre and suburbs, the changes between current and centre calculations are minor (Table 4). These clusters have the lowest sum of housing and commuting costs, and thus, they are most favorable housing sites if jobs concentrate to the centre and rural industries stagnate like in the past few years.

\section{Discussion and Conclusions}

The results of the article show that the population growth in centre of working regions does not extend to distant rural areas, and instead leads to population losses in remote areas due to backwash effects. Thus, rural development based on the centre's spread effects cannot be considered as a sustainable development strategy outside the fringe areas, even if this "radiation" effect has been the backbone of many regional policy programmes in Finland [29]. The spread effects of the centres were geographically limited ranging from less than an hour's drive from the centres. This reflects that commuting has relatively higher cost impact than, for example, in the distant areas of North America [2]-[5] [27]. As the economic growth is not spreading in sparsely populated areas, the results support the use of more tailored place-based policy approaches, including cost reductions, in areas between the growing centres to find new opportunities to support their development and avoid welfare losses.

As our results show, the development is likely to bring even narrower geographic spread effects if the commuting costs increase, or if the community structure is controlled, for example, with taxes, to be more stringent. At the moment, the tax deduction of the travel expenses extends about 40 kilometres from the centre and the areas located outside this limit experience higher distance costs than areas located within $40 \mathrm{~km}$ from the centre. The high sum of the housing and commuting costs encourage especially low-income households to migrate from remote locations closer to the centre because housing costs are not declined in relation to increased commuting costs. Therefore, it seems that potential spread effects actualize as potential backwash effects in the remote rural areas, and the potential spread effect can work only in the limited rural areas next to the urban core [23] [25]. Thus, remote rural areas have been exposed to negative net migration as earlier studies have shown [12] [26] [27]. This article has focused on Finland but the results can be applied to other similar sparsely-populated regions as well with similar physical and institutional settings.

In theory, results also show that migration barrier, the situation where the rural households are unable to buy a house from centre or are unable commute to work from the current location to centre is possible for households with low incomes. In the long run, this threat can lead to a situation where agglomeration economies are lost due to overheating of housing markets and the growth of centres turn into recession. The threat is consisted of the three factors that are influencing the same time. The first factor depends on the low disposable income of the low-income households emphasized in the Helsinki working area where the high costs of housing might decline the opportunities for low-income households to migrate close to centre. The problem is that if housing costs continue to rise, households' disposable income can be below 20 percent of the household's total income. The second factor is related to the current housing location of the household. If the current location of household is at the edge of the working region, the commuting cost to center might be so high that the commuting is not economically feasible. In this case, it is economically more profitable not to commute to the work and be an unemployed than use the income from work to high commuting costs. The third factor is related to capital income of the household apartment, which can turn to be negative, if the apartment is located in an area where housing prices are falling. This factor can decline the willingness of migration closer to centre because the price difference of apartments in centre and distant areas can become too high. Decreasing property and the other factors mentioned above could together lea to a trap where a household does not have an opportunity to migrate closer to centre nor economically viable to commute there either. A possible decline in the value of apartment increases the risk of poverty.

The outcome of above described migration barrier would be the welfare losses due to the formation of idle human resources. From the perspective of rural development, this kind of development is not desirable [12]. The comparison of the results in the current and centralised regional structures and policies emphasizes the importance of a smaller centre and their labour market in the development of rural areas. Due to the high location disadvantage the distant areas are unable to benefit from potential spread. Thus, the problem is that these distant 
areas are highly dependent on the existing economic structure, and are unable to take part in technology-driven economic growth, which requires assets of a new kind: human capital and environment that make possible the exploitation of the economies of scale. To overcome the mismatch of the supply and demand for the location factors, rural areas should be supported by place-based policy that attempts to new technologies and production methods [27].

\section{References}

[1] Moss J., Jack, C. and Wallace, M. (2004) Employment Location and Associated Commuting Patterns for Individuals in Disadvantaged Rural Areas in Northern Ireland. Regional Studies, 42, 121-136. http://dx.doi.org/10.1080/0034340042000190118

[2] Partridge, J. and Nolan, J. (2005) Commuting on the Canadian Prairies and the Urban/Rural Divide. Canadian Journal of Administrative Sciences, 22, 58-72. http://dx.doi.org/10.1111/j.1936-4490.2005.tb00361.x

[3] Polése, M. and Shearmur, R. (2006) Why Some Regions Will Decline: A Canadian Case Study with Thoughts on Local Development Strategies. Papers in Regional Science, 85, 23-46. http://dx.doi.org/10.1111/j.1435-5957.2006.00024.x

[4] Partridge, M., Olfert, M.R. and Alasia, A. (2007) Canadian Cities as Regional Engines of Growth: Agglomeration and Amenities. Canadian Journal of Economics, 40, 36-68. http://dx.doi.org/10.1111/j.1365-2966.2007.00399.x

[5] Shearmur, R. and Polése, M. (2007) Do Local Factors Explain Local Employment Growth? Evidence from Canada 1971-2001. Regional Studies, 41, 453-471. http://dx.doi.org/10.1080/00343400600928269

[6] Gløersen E., Dubois, A. Copus, A. and Schürmann, C. (2005) Northern Peripheral, Sparsely Populated Regions in the European Union. Nordregio, Stockholm.

[7] Ali, K., Olfert, M.R. and Partridge, M. (2011) Urban Footprints in Rural Canada: Employment Spillovers by City Size. Regional Studies, 45, 239-260. http://dx.doi.org/10.1080/00343400903241477

[8] Eliasson, K., Lindgren, U. and Westerlund, O. (2003) Geographical Labour Mobility: Migration or Commuting? Regional Studies, 37, 827-837. http://dx.doi.org/10.1080/0034340032000128749

[9] Partridge, M., Rickman, D., Ali, K. and Olfert, M.R. (2010) Recent Spatial Growth Dynamics in Wages and Housing Costs: Proximity to Urban Production Externalities and Consumer Amenities. Regional Science and Urban Economics, 40, 440-452. http://dx.doi.org/10.1016/j.regsciurbeco.2010.05.003

[10] Rouwendal, J. and Meijer, E. (2001) Preferences for Housing, Jobs and Commuting: A Mixed Logit Analysis. Journal of Regional Science, 41, 475-505. http://dx.doi.org/10.1111/0022-4146.00227

[11] Renkow, M. (2003) Employment Growth, Worker Mobility and Rural Economic Development. American Journal of Agricultural Economics, 85, 503-513. http://dx.doi.org/10.1111/1467-8276.00137

[12] Lehtonen, O. and Tykkyläinen, M. (2009) The Emerging Shortage of Labour in Forestry in a Remote Coniferous Region: A Brake on the Massive Use of Biofuels. In: Andersson, K., Eklund, E., Lehtola, M. and Salmi, P., Eds., Beyond the Rural-Urban Divide, Emerald, Bingley, 25-55.

[13] Lehtonen, O. and Tykkyläinen, M. (2012) Spatial Processes of Job Growth in Eastern Finland, 1994-2003. Terra, 123, 85-105.

[14] Sandow, E. (2008) Commuting Behaviour in Sparsely Populated Areas: Evidence from Northern Sweden. Journal of Transport Geography, 16, 14-27. http://dx.doi.org/10.1016/j.jtrangeo.2007.04.004

[15] Krugman, P. (1991) Increasing Returns and Economic Geography. Journal of Political Economy, 99, 483-499. http://dx.doi.org/10.1086/261763

[16] Rosenthal, S. and Strange, W. (2001) The Determinants of Agglomeration. Journal of Urban Economics, 50, $191-229$. http://dx.doi.org/10.1006/juec.2001.2230

[17] Glaeser, E. and Kahn, M. (2003) Sprawl and Urban Growth. National Bureau of Economic Research, Cambridge. http://dx.doi.org/10.3386/w9733

[18] Alonso, W. (1964) Location and Land Use: Toward a General Theory of Land Rent. Harvard University Press, Cambridge.

[19] Muth, R. (1969) Cities and Housing. University of Chicago Press, Chicago.

[20] Mills, E. (1972) Urban Economics. Scott Foresman, Glenview.

[21] Plaut, P. (2006) The Intra-Household Choices Regarding Commuting and Housing. Transportation Research Part A, 40, 561-571. http://dx.doi.org/10.1016/j.tra.2005.10.001

[22] Yousfi, S. (2005) Two-Career Families in the Labor Market. University of Turku, Turku. 
[23] Barkley, D., Henry, M. and Bao, S. (1996) Identifying “Spread” versus "Backwash” Effects in Regional Economic Areas: A Density Functions Approach. Land Economics, 72, 336-357. http://dx.doi.org/10.2307/3147201

[24] Henry, M., Barkley, D. and Bao, S. (1997) The Hinterland's Stake in Metropolitan Growth: Evidence from the Selected Southern Regions. Journal of Regional Science, 37, 479-501. http://dx.doi.org/10.1111/0022-4146.00065

[25] Partridge, M., Bollman, R., Olfert, M.R. and Alasia, A. (2007) Riding the Wave of Urban Growth in the Countryside: Spread, Backwash or Stagnation? Land Economics, 83, 128-152.

[26] Renkow, M. and Hoover, D. (2000) Commuting, Migration, and Rural-Urban Population Dynamics. Journal of Regional Science, 40, 261-287. http://dx.doi.org/10.1111/0022-4146.00174

[27] Partridge, M., Rickman, D., Ali, K. and Olfert, M.R. (2008) Lost in Space: Population Growth in the American Hinterlands and Small Cities. Journal of Economic Geography, 8, 727-757. http://dx.doi.org/10.1093/jeg/lbn038

[28] Goetz, S., Han, Y., Findeis, J. and Brasier, K. (2010) US Commuting Networks and Economic Growth: Measurement and Implication for Spatial Policy. Growth and Change, 41, 276-302. http://dx.doi.org/10.1111/j.1468-2257.2010.00527.x

[29] Moisio, S. (2012) Valtio, Alue, Politiikka: Suomen Tilasuhteiden Sääntely Toisesta Maailmansodasta Nykypäivään. Vastapaino, Tampere.

[30] Lahtinen, M., Laiho, V., Pakarinen, S. and Esala, L. (2012) Development of the Regional Housing Markets to Year 2014. Pellervo Economic Research, Helsinki.

[31] Muilu, T. and Rusanen, J. (2004) Rural Definitions and Short-Term Dynamics in Rural Areas of Finland in 1989-1997. Environment and Planning A, 36, 1499-1516. http://dx.doi.org/10.1068/a36169

[32] Pettersson, Ö. (2001) Microregional Fragmentation in a Swedish County. Papers in Regional Science, 80, 389-409. http://dx.doi.org/10.1007/PL00013630

[33] Hartigan, J.A. and Wong, M.A. (1979) Algorithm AS 136: A K-Means Clustering Algorithm. Applied Statistics, 28, 100-108. http://dx.doi.org/10.2307/2346830

[34] STV (2013) Household Consumption. Statistics Finland, Helsinki.

[35] Siikanen, A., Säylä, M. and Tahvanainen, M. (1999) Housing Costs in Finland. Ministry of the Environment, Helsinki.

[36] FPA (2012) Housing Cost of Detached House. The Social Insurance Institution of Finland, Helsinki.

[37] Trafi (2012) Travel Survey 2010-2011. Finnish Transport Agency, Kuopio.

[38] Hastie, T. and Loader, C. (1993) Local Regression: Automatic Kernel Carpentry (with Discussion). Statistical Science, 8, 120-129. http://dx.doi.org/10.1214/ss/1177011002

[39] Cleveland, W. (1979) Robust Locally Weighted Regression and Smoothing Scatterplots. Journal of the American Statistical Association, 74, 829-836. http://dx.doi.org/10.1080/01621459.1979.10481038

[40] Lyytikäinen, T. and Lönnqvist, H. (2005) Housing Costs in Biggest Regional Centres. Government Institute for Economic Research, Helsinki. 
Scientific Research Publishing (SCIRP) is one of the largest Open Access journal publishers. It is currently publishing more than 200 open access, online, peer-reviewed journals covering a wide range of academic disciplines. SCIRP serves the worldwide academic communities and contributes to the progress and application of science with its publication.

Other selected journals from SCIRP are listed as below. Submit your manuscript to us via either submit@scirp.org or Online Submission Portal.
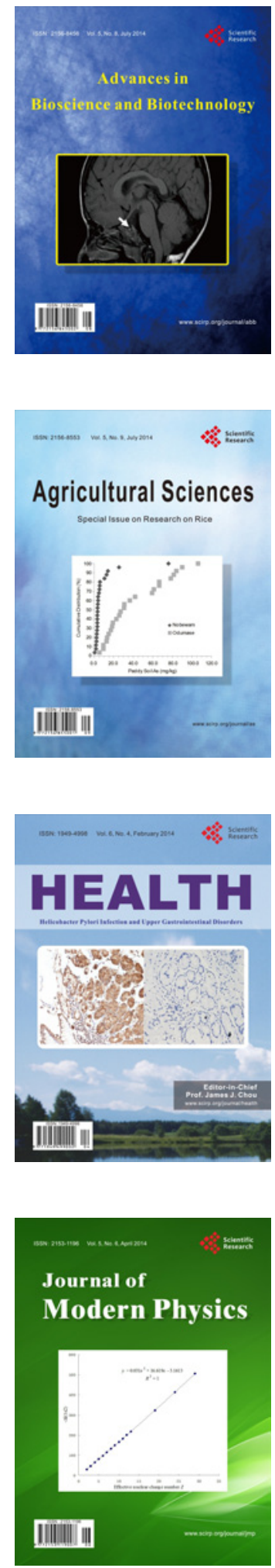
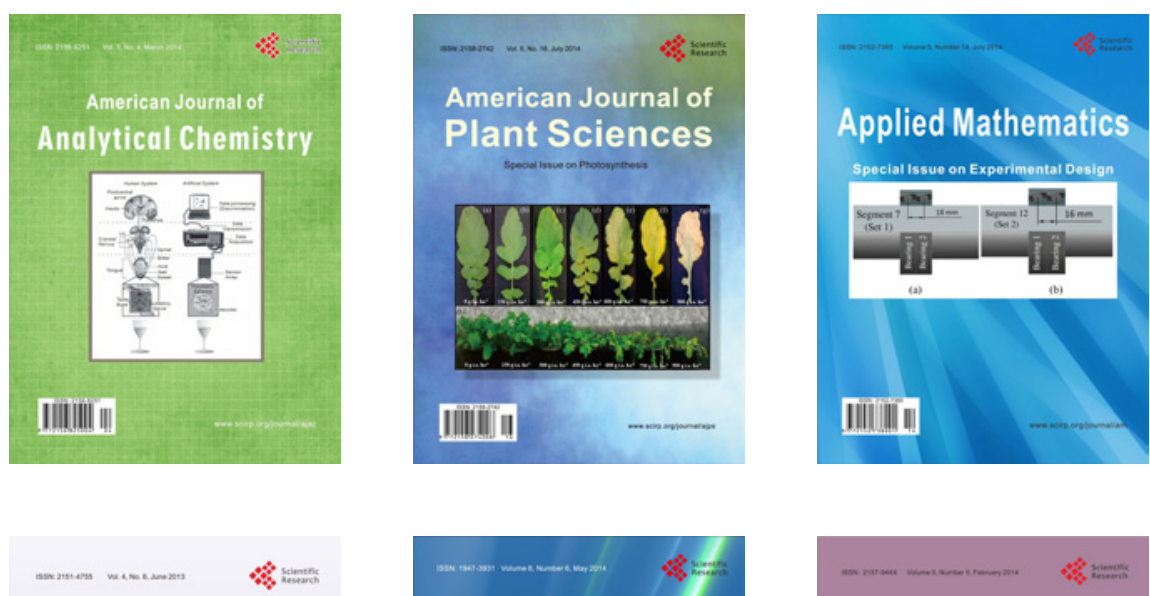

Creative Education
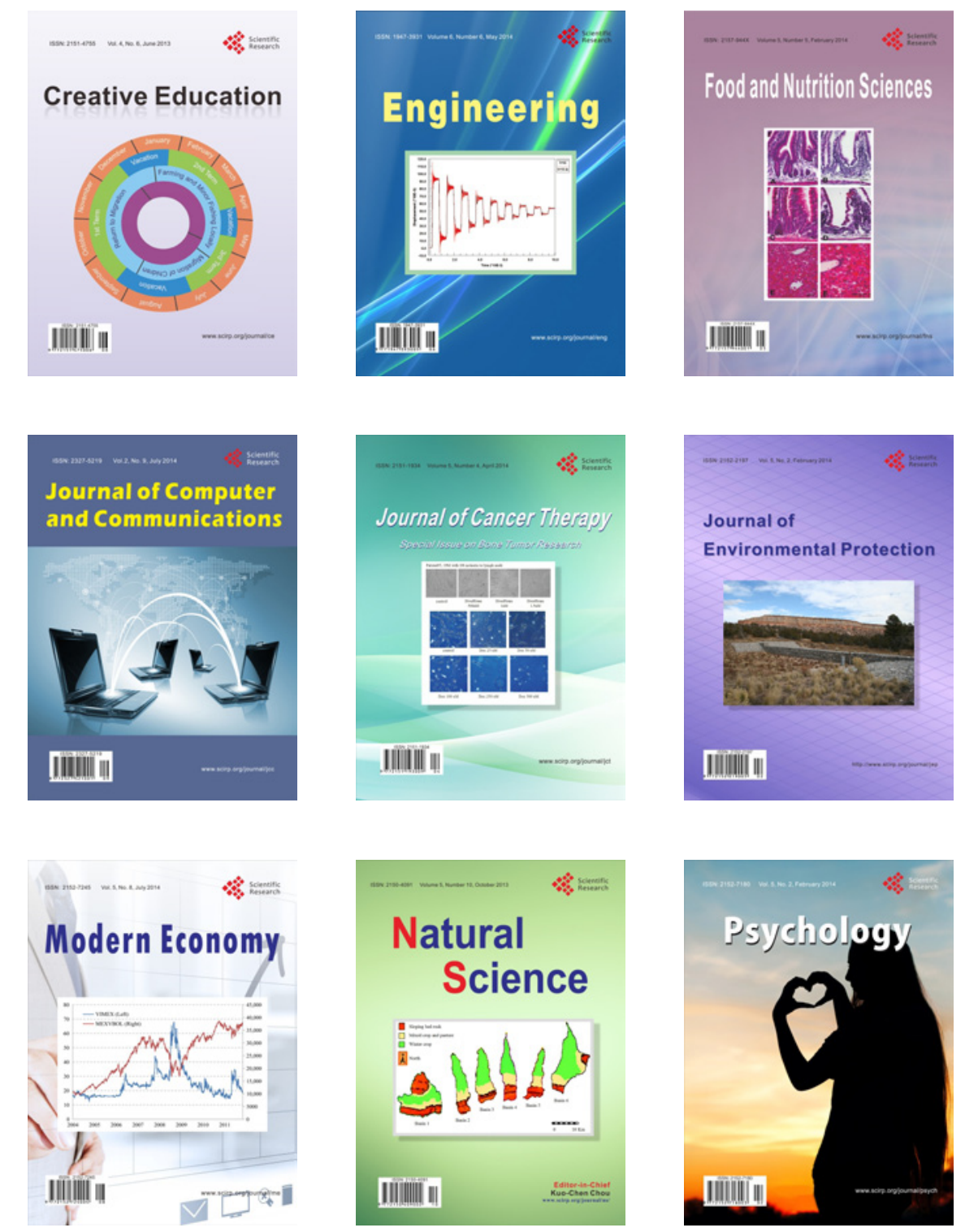